\title{
Comunicação, sistemas complexos e
}

\section{transdisciplinaridade: um comunicar intercientífico}

\author{
Fátima Regis'
}

\begin{abstract}
Resumo
A alta capacidade de processamento de dados viabilizada pelo advento do computador proporciona uma nova forma de empiricidade para testar teorias - as simulaçōes computacionais. Esta nova técnica produz duas novidades. Primeira: permite a investigação dos sistemas complexos, inalcançáveis pelos métodos científicos conhecidos até então. Segunda: por suas caracteristicas intrínsecas, opera entre os terrenos do real e do ficcional. Esses dois aspectos produzem um abalo nas fronteiras epistemológicas modernas, colaborando para a inauguração de um novo paradigma cientifico - a complexidade. O objetivo do artigo é duplo. Primeiro: discutir como a complexidade abala as fronteiras epistemológicas modernas de duas maneiras, mostrando a inter-dependência entre diversas disciplinas e usando um método que agrega aspectos ficcionais à ciência. Segundo: mostrar que as trocas de informação $e$ as interaçōes entre os componentes constituem o cerne dos sistemas complexos. Assim, encaminhamos a hipótese de que o modelo do processo de comunicaçāo torna-se fundador da lógica de funcionamento deste novo paradigma, transdisciplinar por excelência.
\end{abstract}

Palavras-chaves: Comunicação, simulações de computador, ficção, sistemas complexos, transdisciplinaridade

\begin{abstract}
The high capacity of data processing, made possible by the advent of computer technology, brings a new empirical way to test theories - the computer simulations. This new technique presents two improvements. The first one: enables a Investigation of the complex systems, unreachable till then by traditional scientific methods. The second one: due to its intrinsic characteristics, works between real and fictional terrains. These two aspects produce an shake on the modern epistemological frontiers, collaborating to the inauguration of a new scientific paradigm - complexity. This article has a double goal. The first one: discourse how complexity shakes the modern epistemological frontiers by two ways, revealing the interdependence between disciplines and using a method that aggregates fictional aspects to science. Second: show that the informational exchanges and the interactions between components constitutes complex system's core. Thus, we are proposing the hypothesis that the communication model constitutes the founder of the working logic of this new paradigm, fundamentally transdiciplinar.
\end{abstract}

Key words: Communication, computer simmulation, fiction, complex systems, transdisciplinarity

' Fátima Regis ê Professora Adjunta da Faculdade de Comunicaçăo Social da UERJ e Doutora em Comunicaçăo e Cultura pela ECO/UFRJ 
Não é novidade o fato de que o desenvolvimento das tecnologias de informação e de comunicação, a partir da segunda metade do século XX, tem . propiciado uma verdadeira revolução nos campos da economia, comunicação, comércio, sociedade e cultura. $O$ que nem sempre é notado é que neste processo os métodos científicos também não saem ilesos.

A alta capacidade de processamento de dados viabilizada pelo advento do computador proporciona uma nova forma de empiricidade artificial para testar teorias com mais eficácia - as simulações de computador e os 'displays' gráficos. Estas novas técnicas trouxeram duas novidades. Em primeiro lugar, permitiu a investigação dos sistemas complexos, que permaneciam intocados pelos procedimentos científicos conhecidos até então. Em segundo, por suas características intrínsecas, as simulações computacionais atuam entre os campos do real e do ficcional, transformando a própria metodologia da ciência. Esses dois aspectos produzem um abalo nas fronteiras epistemológicas modernas, colaborando para a inauguração de um novo paradigma científico - a complexidade.

O objetivo do artigo é duplo. Primeiro: discutir duas caracteristicas da complexidade que abalam as fronteiras epistemológicas modernas a interdependência entre diversas disciplinas e a técnica de simulação que agrega aspectos ficcionais à ciência. Segundo: mostrar que o cerne dos sistemas complexos reside nas trocas de informação e interações entre os componentes básicos do sistema. Desse segundo objetivo deriva a hipótese de que o modelo do processo de comunicação torna-se fundador da lógica de funcionamento deste novo paradigma, transdisciplinar por excelência.

\section{Sistemas complexos: emergência e auto-organização}

Um sistema é um conjunto de elementos que estão em interação entre si formando um todo único. Grosso modo, podemos dividir os sistemas em duas grandes categorias: simples e complexos.

Sistemas simples são aqueles que têm apenas duas ou três variáveis, como o movimento dos corpos na mecânica clássica. Sistemas deste tipo são tratados desde a ciência clássica por procedimentos de análise. A análise, legado do método cartesiano, prevê a separação do todo em fraçð̃es até que se atinja as partes mais elementares. Isoladas as partes elementares, identificam-se os poucos atributos desses elementos e, a partir desses dados básicos, reconstituem-se as características do sistema como um todo (Cf. OLIVEIRA, 2003, p. 140-1). Pelos procedimentos de análise, considera-se que não há interação entre as partes ou esta é tão fraca que pode ser desprezada para fins de pesquisa. Sem a interação entre as partes elementares, nos sistemas simples, o todo é uma soma das partes e mantém as mesmas propriedades destas. Sistemas simples são reducionistas - porque as propriedades do todo são reduzidas às propriedades das partes simples. 
Os sistemas complexos são descritos como dinâmicos e não-lineares. São sistemas em que o conjunto de todas as variáveis não obedece a uma relação constante de proporcionalidade, mas isto não significa desordem. São sistemas sensiveis às condições iniciais, isto é, de acordo com as variações que ocorram no estado inicial do sistema, sua evolução se torna imprevisível. São por essa razão sistemas de comportamento caótico, pois mudam de estado sob efeito da ação do tempo. Sistemas que podem alterar seu estado de acordo com sensiveis variações nas condições iniciais e com a ação do tempo podem ser ilustrados pela metáfora já famosa do "efeito borboleta". Este efeito foi analisado pela primeira vez pelo matemático Edward Lorenz na década de 1960. Lorenz estudava efeitos climáticos e percebeu que ínfimas mudanças nas variáveis iniciais dos sistemas meteorológicos amplificadas pela ação do tempo poderiam causar alterações drásticas no final do sistema. Explicou sua tese com a analogia de que o simples bater de asas de uma borboleta no Brasil poderia causar um tornado no Texas. A inspiração parece ter origem no conto de fiç̧ão cientifica "A Sound of Thunder" (Um Som de Trovão), publicado em 1952 por Ray Bradbury. A história se passa em uma Terra do futuro, às vésperas das eleiçðes presidenciais americanas. Um grupo de executivos planeja uma viagem no tempo para retornar à era pré-histórica e caçar dinossauros. A companhia que organiza a viagem toma todas as precauções para tornar ínfimo o impacto dos viajantes no ambiente visitado. Por exemplo, para evitar possíveis interferências no fluxo temporal, o dinossauro escolhido para a caça estava fadado à morte em breve por outras causas. Entretanto, um dos viajantes se desvia no traslado original. Ele é resgatado, mas o incidente provoca uma alteração no fluxo espaço temporal da Terra. Quando os viajantes retornam ao seu tempo de origem, descobrem que a eleição presidencial foi vencida por um político do partido republicano dos EUA, que antes da viagem aparecia nas pesquisas de opinião com chances praticamente nulas de ganhar a eleição. Na sola do sapato do viajante, a resposta da alteração sutil na história americana: uma borboleta pisada. Ou seja, a alteração de uma única variável nas condições iniciais provocou uma mudança inusitada no sistema. $O$ conto revela duas características importantes dos sistemas complexos: a extrema sensibilidade a infimas alterações no estado inicial do sistema e a interdependência entre suas variáveis. No conto, uma pequena alteração no sistema natural produz, no futuro, uma mudança expressiva no campo sócio-politico.

Um sistema deste tipo descreve uma situação em que o comportamento do conjunto excede a soma de cada uma de suas partes. O procedimento de análise não é eficaz quando aplicado a sistemas não-lineares.

Warren Weaver, ao escrever a introdução do famoso livro de Claude Shannon A teoria Matemática da Comunicação classificou os sistemas complexos como sistemas de complexidade desorganizada e sistemas de complexidade organizada. 
Os sistemas de complexidade desorganizada caracterizam-se por terem milhões ou bilhões de variáveis. Nesses sistemas não é possível fazer prognósticos sobre o comportamento de algum elemento isoladamente, mas pode-se fazer previsões exatas sobre o comportamento global do sistema. Como exemplo podemos citar o movimento randômico executado pelas moléculas de um gás à medida que colidem umas com as outras. Dado seu comportamento caótico é impossível conhecer detalhadamente os estados microscópicos e prever a partir das leis do movimento como uma molécula individualmente irá se comportar. Este tipo de sistema só começou a ser estudado a partir do século XIX com a criação dos métodos estatísticos e probabilísticos. Steven Johnson explica que este tipo de sistema é complexo "porque há muitos agentes se inter-relacionando, mas é desorganizado porque eles não criam qualquer comportamento de nivel superior, além de amplas tendências estatísticas" (2003, p. 35) Além dos gases, outros exemplos são os sistemas de seguros, a previdência e os modelos de hereditariedade em uma combinação de genes.

Entre os sistemas simples de duas variáveis e os complexos desorganizados de dois bilhões de variáveis, Warren Weaver identificou um campo intermediário: sistemas que possuem um número moderado de variáveis, no qual as partes elementares interagem entre si, formando padrões de comportamento observáveis no nível macro, compatíveis com um todo organizado. Weaver verificou que esses sistemas possuiam uma complexidade

154 organizada. Esses sistemas organizados precisam ser investigados como um todo, porque seu comportamento é produzido pela interação entre as partes constituintes. Mesmo que se entendam quais as propriedades da matéria e como cada parte funciona isoladamente, não é possível prever o comportamento do conjunto. O comportamento não é propriedade dos elementos da matéria, ele emerge da interação entre os componentes da matéria. As características ou comportamento que surgem não são redutíveis às propriedades ou comportamentos das partes elementares.

Diferente dos sistemas simples em que praticamente não há interação entre os agentes elementares, nos sistemas de auto-organização a efervescência de interações entre as partes elementares é a cerne do sistema. Essas partes simples interagem entre si por meio de regras especificas e locais (não programadas por um agente de nível superior) criando um comportamento observável no nível macro ou, com o passar do tempo, gerando um padrão especifico ordenado, ou seja, produzem o fenômeno da auto-organização.

Para entendermos melhor o que é e como funciona na prática o fenômeno da auto-organização, tomemos um exemplo prático: o caso das formigas $^{2}$

Quando observamos uma formiga isoladamente, não conseguimos discernir nenhum objetivo em sua trajetória. No entanto, quando essa formiga 
descobre uma fonte de alimento, algo de curioso ocorre. Ela toma uma amostra do alimento e - assim como as migalhas de pão marcam o trajeto de João e Maria, graças à trilha de feromônios que deixou no chão, a formiga refaz seu percurso até o formigueiro. Durante o caminho de volta, encontra uma segunda formiga. Após avaliar o valor nutritivo do alimento com suas antenas, a segunda formiga realiza o seguinte procedimento com o objetivo de alcançar a fonte de alimento: divide o mundo em dois hemisférios - a área de onde ela própria vinha e área de onde vinha a primeira formiga - e começa a investigar a área de onde provinha a primeira formiga. Uma terceira formiga se aproxima e repete o mesmo procedimento. Divide o mundo em duas partes: a sua e a parte em que se concentram as duas primeiras formigas. Cada formiga que chega repete o procedimento, de modo que lá pela ducentésima, o resultado é um caminho único que liga o formigueiro à fonte de alimento. Esse caminho é sempre o mais curto e o mais econômico. O que podemos concluir com este exemplo é que uma formiga isolada parece ziguezaguear sem finalidade, mas um grupo de formigas gera um padrão específico (a trilha) que representa a solução de um problema. A partir da repetição de regras de interação extremamente simples - seguir as trilhas mais ricas em feromônios - emerge um comportamento de conjunto cuja intenção e eficácia são claramente observáveis no nivel macro. Como conclui Luiz Alberto Oliveira "há portanto capacidades na ação coordenada de duzentas formigas que não estão presentes nas formigas individuais; um predicado novo foi acrescentado, uma nova qualidade emergiu." (2003, p. 145) Ou seja, diferentemente de um sistema simples, no sistema complexo colônia de formigas há propriedades do todo que são irredutíveis às propriedades dos agentes elementares.

A auto-organização envolve a emergência (e manutenção) da ordem, ou complexidade, a partir de uma origem ordenada em um nível inferior. Não significa apenas mudanças superficiais, mas implica um desenvolvimento fundamental da estrutura. Este desenvolvimento é 'espontâneo' ou 'autônomo' obedecendo a características intrínsecas ao próprio sistema, que freqüentemente está interagindo com o mejo ambiente, em vez de ser imposto ao sistema por um programador externo. (Cf. BODEN, 1996, p. 3) O modelo da auto-organização é um modelo de um mundo sem líderes, em que o comportamento emerge a partir de interações entre os elementos simples nos níveis inferiores. O clima, a vida, a sociedade, as colônias de formigas e o mercado financeiro são sistemas desse tipo.

Um outro exemplo de auto-organização, mais palatável para nossa área, é o da emergência de padrões em ambientes urbanos. Em 1842, Friedrich Engels chega à cidade de Manchester para supervisionar a fábrica de algodão pertencente à família. Engels que já era amigo de Marx, usou os três anos que passou em Manchester, patrocinado por sua familia burguesa, realizando as pesquisas que deram origem a um dos tratados sobre urbanismo no século XIX, A condição da classe operária na Inglaterra. Manchester é 
reconhecidamente uma cidade que foi construida sem nenhum tipo de planejamento. Mas, Engels verifica que no meio do crescimento desordenado pode-se identificar um estranho padrão.

A própria cidade é construída de uma maneira peculiar, de modo que uma pessoa pode morar nela durante anos, entrar e sair dela diariamente sem ter contato com um bairro popular e nem mesmo com operários quer dizer, contanto que a pessoa se limite aos seus próprios negócios ou a passear por puro prazer. Isto decorre principalmente das circunstâncias de que, através de um acordo tácito e inconsciente, assim como de uma intenção explícita e consciente, mantêm os bairros populares totalmente separados das partes da cidade reservadas à classe média...

Sei muito bem que essa maneira enganosa de construir é mais ou menos comum a todas as grandes cidades. Sei também que, em virtude de seu tipo de negócio, os comerciantes precisam alojar-se nas vias principais, de muito movimento. Sei que nessas ruas, há mais casas boas do que casas humildes, e que o valor do terreno é mais alto nas redondezas do que nos locais mais afastados. Mas, ao mesmo tempo, em nenhum outro lugar, a não ser em Manchester, vi um isolamento tão sistemático das classes operárias. Nunca vi em outro lugar ocultarse com tão fina sensibilidade tudo que pudesse ofender os olhos e os nervos da classe média. E, no entanto, mais do que acontece com qualquer outra cidade, Manchester, foi construida com menos planejamento e menos restrições por parte de regulamentos oficiais do que qualquer outra cidade - na verdade, cresceu ao acaso. Ainda assim... não consigo deixar de sentir que os industrialistas liberais, os 'bigwigs' de Manchester, não são inocentes desse estilo acanhado de construção. (ENGELS apud JOHNSON, 2003, p. 26-27)

Como Johnson destaca o que Engels distinguiu no cenário urbano foram padrões visíveis porque têm uma estrutura repetitiva que os distingue do mero ruído de fundo. São sinais emergindo de um lugar do qual só poderíamos esperar ruídos. (Cf. JOHNSON, 2003, p. 29)

Essas estruturas emergentes não são criadas por leis governamentais ou projetos urbanos. São criadas por milhões de indivíduos e algumas regras simples de interação social. Tradicionalmente, os indivíduos se aproximam de seus pares e mantêm distância tácita com os diferentes, os 'outros'. Já os comerciantes precisam se estabelecer em locais de grande circulação de pessoas. Essas regras simples de 'convívio social' 'empurram' as classes desfavorecidas para os lugares mais escondidos da cidade. 


\section{Simulação de computador e a nova metodologia cientifica}

\subsection{Da análise à síntese}

Antes da invenção do computador, os cientistas conseguiam investigar os sistemas simples e os sistemas de complexidade desorganizada. Os primeiros eram tratados por equações analíticas. Já os sistemas de complexidade desorganizada eram tratados por métodos estatísticos e probabilísticos. O computador permitiu o estudo dos sistemas de autoorganização, expandindo imensamente as possibilidades de investigação dos sistemas.

Vamos tentar compreender como isso ocorre: os componentes fundamentais e as leis que regem os comportamentos mecânico, elétrico e químico são bem conhecidos. A dificuldade reside em prever como o conjunto dos componentes irá se comportar, dado que alterações ínfimas nas condições iniciais e a interdependência das variáveis geram efeitos completamente inusitados no final do sistema. Por exemplo, a meteorologia conhece os componentes e as equaçóes atmosféricas, mas para prever o tempo, precisa calcular as "implicações das interações de um vasto número de variáveis partindo de complicadas condições iniciais" (SIMON, 1999, p. 15). Na ausência do computador, os pesquisadores precisavam utilizar cálculos integrados de modo que as equações fossem integradas sucessivamente, simulando o desdobramento do comportamento do sistema com a passagem do tempo. Sem o computador, a tarefa era praticamente inexequível. Para desvendar os mistérios desse tipo de sistema é preciso modelar o comportamento do sistema quase que em tempo real. Isto só se tornou possível com o desenvolvimento das simulações de computador.

Para produzir simulações, o computador utiliza procedimentos de sintese. Diferente do método analítico - em que a pesquisa começa com o comportamento de interesse e decompõe (analisa) o todo em suas partes constituintes -, a síntese inicia com as partes constituintes, colocando-as juntas na tentativa de sintetizar o comportamento de interesse.

A partir de descrições pormenorizadas de componentes e leis de comportamento mecânico, elétrico e químico, o computador calcula a evolução do comportamento dos sistemas a partir de uma ampla faixa de parâmetros e condições iniciais, permitindo criar praticamente todos os fenómenos possiveis, existentes ou não. Aqui já começamos a vislumbrar como surge o poder da ficção associado às tecnologias informacionais: os modelos de computador permitem criar não apenas as situações atuais ou as prováveis, mas todas as situações possiveis e até as praticamente impossiveis. Por exemplo, os simuladores de vôo mais modernos modelam não apenas todo tipo de situação que o piloto enfrentará na realidade, mas também condições climáticas extremamente improváveis como nevar no Rio de Janeiro (KENSKI, 
2001, p. 67). Um piloto em treinamento pode "experimentar" como é decolar do Aeroporto Santos Dumont sob uma nevasca na Baía de Guanabara.

A miríade de sistemas que podem ser simulados transformou 0 computador em uma ferramenta presente praticamente em todos os campos de pesquisa. É possível sintetizar situações variadas tais como condições climáticas nos quatro cantos da Terra, comportamento de colônias de insetos e, até mesmo, os fluxos populacionais de grandes cidades. Mas os milagres operados pelas novas técnicas computacionais não param por aqui. Com os procedimentos de síntese, os cientistas tiveram um insight notável: o uso da simulação para investigar sistemas físicos complexos ensinou que "comportamento complexo não precisa de raízes complexas" (Langton, 1995, p. ix). Isto significa que os cientistas perceberam que suas pesquisas não precisavam se limitar a simular os sistemas existentes, mas poderiam colocar juntas substâncias e partes da matéria que não aparecem juntas na natureza e ver que outros sistemas poderiam emergir dessas interações. Dito de outra forma, significa que os procedimentos de síntese dotaram os cientistas de um poder maior do que imitar a natureza.

Sintetizar é mais do que reproduzir em laboratório os processos naturais, é criar objetos e substâncias que não existem na natureza. É o caso da química sintética. Foi somente quando, por meio do processo de sintese, "colocou-se os pedaços constituintes da matéria juntos em novas e diferentes formas que foi possivel ampliar o conjunto de compostos químicos disponiveis

158 para estudo muito além do conjunto provido pela natureza" (LANGTON, 1995: p.X). Quando puderam ver além da natureza acidental dos compostos químicos naturais, os pesquisadores vislumbraram as regularidades na constituição da matéria. "Para se ter uma teoria do atual, é necessário entender o possivel", assevera Christopher Langton, o pai da biologia sintética (1995: p.x).

Um dos exemplos em que esta técnica foi extremamente útil e bem sucedida foi a criação do antibiótico sintético Zyvox, desenvolvido para combater as bactérias mutantes e resistentes aos mais potentes antibióticos existentes até então. Os cientistas forneceram ao computador todas as informações disponiveis sobre a biologia dos micróbios. Tomando por base os "pontos fracos" das bactérias, o computador simulou inúmeras substâncias inexistentes na química e as testou virtualmente, até chegar à linezolida. Totalmente sintética, a molécula de linezolida jamais foi vista por um microorganismo: sua aparição surpreende as bactérias que invade, destruindoas sem que possam se defender (LUCIRIO \& MENAI, 2000, P. 78).

A sintese ensinou a projetar outras possibilidades da natureza; criar "realidades alternativas", como as descrevem os escritores de ficção científica. Sintetizar é criar mundos possiveis. Quando falamos de mundos possíveis, já estamos no campo da ficção. 


\subsection{A ciência-ficção}

Se na Idade Média, a imaginação era considerada como um dos elementos do saber que operava por semelhanças (Cf. FOUCAULT, 1992), após a Revolução Científica do século XVIl a imaginação torna-se fonte de erro, dissociando-se das formas de produção de conhecimento. Com a divisão dos campos do saber efetuada pela epistéme moderna, à ciência coube a nobre tarefa de investigar a composição e funcionamento dos objetos e fenômenos naturais. A função de construir coisas artificiais - como fazer artefatos que tenham as propriedades desejadas e como projetá-los - foi designada ds escolas de engenharia. A imaginação ficou com a tarefa de fantasiar sobre os mundos possíveis - aqueles que não são nem os naturais (atuais, existentes), investigados pela ciência, nem os artificiais (projetados pelos engenheiros por sua praticidade e/ou aplicabilidade) -, relegada ao campo das obras de ficção.

A fiç̧ão nasce na Modernidade com o propósito de diferenciar-se da fábula. Esta, associada ao período pré-moderno, conta os grandes feitos e as aventuras fantásticas, inomináveis, nos deixando no terreno indeciso entre o verdadeiro e o falso. A ficção opera no campo do falso e do artifício, mas compromete-se a produzir efeitos de verdade como tal reconheciveis (FOUCAULT, 1992, p. 126). É o acordo tácito entre autor e leitor. O leitor sabe que a obra é uma fiç̧ão, um artificio, mas o autor a cria com uma verossimilhança que mantém a credulidade do leitor. Desde então, a ficção trata dos mundos possíveis, aquilo que não é, mas poderia ser.

Embora não possua visto para transitar por terrenos científicos, a ficção sempre teve sinal verde nos campos da engenharia. Um exemplo recente saiu na Folha de São Paulo (BILLEN, 2006): Marc Rayman, engenheiro-chefe do departamento de propulsão da NASA confessou que a inspiração para a propulsão à base de ferro veio de um episódio da série de TV já clássica Jornada nas Estrelas.

Como se sabe, a engenharia opera com os métodos do design. $\mathrm{O}$ design é a arte de projetar mudanças de situações existentes por outras preferenciais. Hoje, quando os processos de sintese se integram aos métodos científicos, a ciência passa a atuar como design e a ficção agrega-se à realidade por uma forma que até então the era interditada - a prática científica. Ao projetar não apenas os mundos existentes, mas também os possiveis, a simulação revela-se um método entre o real e o ficcional.

Simular ou criar modelos não é um procedimento científico novo. A originalidade também não está em fabricar artefatos e instrumentos que não existem na naturcza. A novidade consiste na possibilidade de intervir sobre os mecanismos da vida, até então fora do alcance da ciência. A novidade consiste na possibilidade de manipular genes intra e inter espécies, resultando em criação, modificação, clonagem e hibridação de seres (ou partes de) vivos. 
Tornando imprecisas as fronteiras entre o fisico e o não-fisico, o natural e o artificial, a engenharia genética - ciência do design por excelência - e as tecnologias da informação prometem remodelar o mundo e o ser vivo com um vigor sem precedentes.

E agora não estamos falando de ficção, mas de entidades existentes, aquelas descritas nas manchetes de jornal: alimentos transgênicos como a soja e o milho híbrido, experiências de laboratório como a ovelha clonada Dolly. A ciência passa a produzir seres e mundos possiveis que anteriormente habitavam apenas as histórias de ficção científica. Os monstros, que despertam fascínio e medo, escapam dos livros e filmes de ficção científica e se materializam em nossos laboratórios (Cf. REGIS, 2002).

$\mathrm{Na}$ Atualidade, a quebra de fronteiras entre natural e artificial é qualitativamente distinta da proposta nos tempos de Descartes e Bacon. No período clássico, pensadores como Descartes e Bacon confiam nas artes técnicas desenvolvidas pelo homem-Deus porque estas produziam representações (modelos mecânicos ou matemáticos) fidedignas dos objetos e fenômenos naturais. Hoje, o "cientista-Deus" não apenas recria objetos em laboratório segundo a composição química exata, como sintetiza substâncias "que não ocorreram à Mãe-Natureza", reivindicando a co-autoria do mundo junto a ela. $O$ desejo cartesiano de se tornar senhor e mestre da natureza não apenas é alcançado, mas superado.

\section{Comunicação, complexidade e análise transdisciplinar: um comunicar intercientífico}

O que há em comum nas manifestações populares de protestos contra a globalização em Seattle, na efervescência da cidade de Manchester, no comportamento das formigas ou no uso de softwares como o Simcity, é que todos são sistemas de auto-organização. Todos partem de agentes simples que interagem entre si segundo regras locais e como resultado produzem um padrão reconhecível a nível macro.

Seja por meio de sinais semioquímicos como os feromônios usados nas comunicações entre formigas, ou todo tipo de códigos complexos (gestuais, verbais, arquitetônicos, vestuário etc) usados pelos humanos em suas interações diárias, é o processo de troca de informação que permite as aproximaçס̃es ou afastamentos entre as partes elementares de um sistema, gerando a criação de padrões de comportamento observáveis no nivel macro.

A base dos sistemas complexos é o reconhecimento de padrões. Reconhecer padrões é criar uma sinalização, é criar uma diferença. Um sinal é um padrão que se destaca do ruído de fundo; é uma figura que se destaca de um fundo. É por isso que na Teoria da Informação de Shannon/Weaver, informação é do campo da ordem e da diferenciação, contrapondo-se à entropia que é associada à desordem e à indiferenciação. 
A informação é um padrão que se destaca de um fundo. Reconhecer um padrão é codificar um sinal, é produzir uma linguagem, é um tipo de comunicação.

Certamente que para postular que a comunicação é a base dos sistemas complexos, temos que partir de uma visão ampliada da comunicação, na qual o fenômeno comunicativo abrange níveis humanos e não-humanos.

Lúcia Santaella (2001, p. 16-18) aponta vários autores (entre eles, Nöth e Meyer-Eppler) que defendem que o processo de comunicação inclui os estimulos e sinais detectáveis fisica, química ou biologicamente pelos seres vivos. O fenômeno comunicativo deve abranger desde as interações rudimentares até as linguagens mais complexas.

Neste sentido, a definição de comunicação de Ruesch é bem adequada para pensarmos os sistemas complexos:

Uma ação torna-se uma mensagem quando é percebida tanto pelo próprio ser quanto por outras pessoas. Em outras palavras: os sinais de trânsito se tornam mensagens quando há um receptor que, no lugar de destino, pode avaliar o significado destes sinais. Tal definição inclui a comunicação entre seres humanos e animais, assim como entre os próprios animais. De fato, todos os organismos biológicos, incluindo as plantas, recebem, avaliam e enviam mensagens. Resumindo: a comunicação é um principio de organização da natureza" (RUESCH apud SANTAELLA, 2001, p. 19-grifos nossos)

Juan Díaz Bordenave também defende que a troca de informação é uma atividade processada por sistemas não-humanos. Para o autor, a troca de informações é um "processo de inter-relação e influência reciproca entre uma forma de organização e seu meio ambiente". Esse processo é comum a mecanismos mecânicos (um relógio), mecanismos homeostáticos (um termostato), organismos biológicos (uma célula / órgãos do corpo humano), organismos vegetais, organismos animais (dança das abelhas), seres humanos, organizações sociais (a comunicação como ingrediente de interação nos sistemas sociais) e entre organizaçðes (empresas, comunidade, sociedade, governo, clubes, associações religiosas). (Cf. BORDENAVE, 1983, p. 11-20)

\subsection{A análise transdisciplinar}

O fenômeno da complexidade só pôde ser observado quando várias ciências perceberam o surgimento de padrões semelhantes em sistemas de áreas distintas como os padrões de funcionamento das sinapses no cérebro e sua analogia com os fluxos das grandes cidades ou as descargas de raios e sua semelhança com as nascentes de rios. Sistemas complexos são transdisciplinares por excelência. 
Segundo Márcio Tavares D’Amaral podemos fazer a seguinte distinção entre os termos multidisciplinar, interdisciplinar e transdisciplinar.

Multidisciplinares são aqueles empreendimentos científicos em que diversos especialistas, sem abrirem em nada mão de sua especificidade, concorrem para a descrição de um mesmo objeto sob variados enfoques. Eles não criam um novo objeto, mas the agregam valores novos, de certa forma o enriquecem sem que, no entanto, cada uma das ciências participantes desses empreendimentos saia deles alterada na sua estrutura, nos seus métodos ou nos seus limites. (D'Amaral 1995, p. 86-87)

Como exemplo podemos pensar nas equipes de saude multidisciplinares, nas quais diversos especialistas como nutricionistas, assistentes sociais, dentistas, psicólogos e profissionais das diversas especialidades médicas analisam os casos dos pacientes atendidos com 0 objetivo de prestar atenção integral à saúde da população-alvo.

Interdisciplinares são as experiências em que o objeto de estudo é colocado na fronteira entre duas ou mais ciências obrigando-as a somar seus esforços para redefinir o objeto. São exemplos as ações da biofísica, da físicomatemática entre outras. Aqui as bordas entre as ciências podem ser ampliadas ou até redefinidas, mas o objeto permanece como um sistema simples, mantendo os mecanismos reducionistas da ciência clássica.

A transdisciplinaridade (trans = para além de) surge da tentativa de se pensar para além dos limites das ciências. Parte do pressuposto de que o real é hiper-complexo, não redutível aos métodos deterministas e reducionistas da ciência clássica. Para dar conta da multiplicidade complexa do real é preciso pôr em comunicação ciências que se distinguem pelo método, mas têm em comum a investigação da complexidade do mundo. D'Amaral assegura que "a condição absoluta para a geração de métodos, conceitos e teorias transdisciplinares é, portanto, um comunicar intercientífico". (1995, p. 91) D'Amaral defende que há comunicação no núcleo de estruturação da ciência. Para ele, "o modelo do trabalho transdisciplinar é um modelo-comunicação" (1995, p. 91).

Só por meio da análise transdisciplinar conseguimos observar os fenômenos complexos. A base dos sistemas complexos é um comunicar intercientífico. Neste novo método de produção de conhecimento, há um rompimento claro com a ciência clássica e uma problematização de suas fronteiras epistemológicas modernas. É neste sombreamento nas fronteiras entre ficção e ciência, mito e razão, natural e artificial que visualizamos um potente abalo nas concepçð̃es epistemológicas modernas. Não como uma vitória do mito, da emoção e da ficção sobre a razão, o que apenas manteria o 
dualismo do pensamento racional moderno, mas sim como convite para o pensamento da multiplicidade do real e de suas fronteiras complexas.

\section{Referências bibliográficas}

BODEN, Margareth A. (ed.). The philosophy of artificial life. New York: Oxford University Press, 1996.

BORDENAVE, Juan Díaz. Além dos meios e das mensagens: introdução à comunicação como processo, tecnologia, sistema e ciência. 5 ed. Petrópolis: Vozes, 1983.

BRADBURY, Ray. "Um Som de Trovão". In: Os frutos dourados do sol. São Paulo: Editora Círculo do Livro, 1979.

CASTELLS, Manuel. A sociedade em rede. Rio de Janeiro: Paz e Terra, 2001. D'AMARAL, Márcio Tavares. O homem sem fundamentos: sobre linguagem, sujeito e tempo. Rio de Janeiro: Editora UFRJ/Editora Tempo Brasileiro, 1995. FOUCAULT, Michel. "A vida dos homens infames". In: O que é um autor?. Lisboa: Veja, 1992.

Fontes, 1992,407p. . As palauras e as coisas. $6^{\text {a }}$. Ed. São Paulo: Martins

JOHNSON, Steven. Emergência: a dinâmica de rede em formigas, cérebros, cidades e softwares. Rio de janeiro: Jorge Zahar Editor, 2003, 231p.

KELLY, Kevin. Out of control: the new biology of machines, social systems, and the economic world. Cambridge, Massachusetts, 1994.

LANGTON, Christopher G "Artificial Life". In: BODEN, Margareth A. (ed.). The philosophy of artificial life. New York: Oxford University Press, 1996.

(ed.) Artificial life. The MIT Press, 1995. . "Introduction". In: LANGTON, Christopher

OLIVEIRA, Luiz Alberto. "Biontes, bióides e borgues". In: NOVAES, Adauto (org.). "O homem-máquina: a ciência manipula o corpo". Rio de Janeiro: Companhia das Letras, 2003.

REGIS, Fátima. Nós, ciborgues: a ficção cientifica como narrativa da subjetividade homem-máquina. (2002) Rio de Janeiro: Universidade Federal do Rio de Janeiro / Escola de Comunicação (Tese de Doutorado) SANTAELLA, Lúcia. Comunicação e Pesquisa. São Paulo: Hacker Editores, 2001,216p.

SHANNON, Claude \& WEAVER, Warren. Teoria Matemática da Comunicação. Rio de Janeiro: Difel, 1975.

SIMON, Herbert. A. The sciences of the artificial. 3 ed. The MIT Press, 1999.

\section{Periódicos:}

BILLEN, Andrew. A fronteira final do marketing: Documentário mapeia a herança cultural, científica e publicitária da série "Jornada nas Estrelas". Folha de São Paulo, São Paulo, 26 de julho de 2006. 


\section{Contracampia}

LUCIRIO, Ivonete, MENAI, Tânia. Bactérias em pânico. Superinteressante, São Paulo, jun de 2000.

KENSKI, Rafael. A arte de voar sem sair do chão. Superinteressante, São Paulo, jun de 2001.

\section{Notas}

' Este exemplo foi resumido a partir do excelente artigo "Biontes, bioides e borgues", de Luiz Alberto Oliveira. In: NOVAES, Adauto (org.). "O homemmáquina: a ciência manipula o corpo". Rio de Janeiro: Companhia das Letras, 2003. 